\title{
Impact of Wide Hybridization on Highbush Blueberry Breeding
}

\author{
Patricio A. Brevis ${ }^{1,2}$ \\ Department of Horticulture, Michigan State University, A316 Plant and Soil Sciences Building, East \\ Lansing, MI 48824 \\ Nahla V. Bassil \\ USDA-ARS, National Clonal Germplasm Repository, 33447 Peoria Road, Corvallis, OR 97333
}

James R. Ballington

Department of Horticultural Science, North Carolina State University, 260 Kilgore Hall, Raleigh, NC 27695

\author{
James F. Hancock \\ Department of Horticulture, Michigan State University, A342 Plant and Soil Sciences Building, East \\ Lansing, MI 48824
}

\begin{abstract}
AdDitional INDEX wORDS. Vaccinium corymbosum, wild germplasm, tetrasomic inbreeding coefficient, simple sequence repeat

Abstract. The use of interspecific hybridization in blueberry (Vaccinium L. section Cyanococcus Gray) breeding has resulted in the incorporation of novel traits from wild germplasm and the expansion of the geographic limits of highbush blueberry $(V . \times$ corymbosum $L$.) production. The objectives of this study were: 1$)$ to estimate the impact of wide hybridization on inbreeding, heterozygosity, and coancestry of the cultivated tetraploid highbush blueberry; 2) to establish the usefulness of microsatellite markers in assessing genetic relationships among southern highbush blueberry [SHB $(V$. $\times$ corymbosum $)$ ] cultivars; and 3$)$ to report on the expected genetic contribution of wild $V$ accinium clones to SHB cultivars. Pedigrees of $\mathbf{1 0 7}$ highbush blueberry cultivars were used to calculate tetrasomic inbreeding coefficients $(F)$, pedigree-based genetic distances, and expected genetic contributions of wild clones. Genotyping data from 21 single-locus microsatellite markers screened across 68 genotypes were used to calculate heterozygosity and proportion of shared alleles distances $\left(\mathrm{D}_{\mathrm{sa}}\right)$. The results indicated that the effects of wide hybridization on genetic diversity of cultivated blueberry were lower than previously thought. First, SHB cultivars exhibited similar levels of molecular relatedness as historical northern highbush blueberry [NHB $(V$. $\times$ corymbosum $)$ ] cultivars $\left(\right.$ median $\mathrm{D}_{\text {sa }}$ between pairs of cultivars equals 0.19 in both cultivar groups), despite the broader genetic base and larger pedigree distances in the former cultivar group. Second, levels of heterozygosity in modern NHB cultivars were not statistically different from those of SHB $\left(\chi^{2}=4.0 ; \mathrm{df}=3 ; P>0.05\right)$, despite the considerably higher levels of inbreeding in the former cultivar group (median $F$ equal to 0.0035 and 0.0013 , respectively). Furthermore, pedigree-based genetic distances were significantly correlated with $D_{\mathrm{sa}}(r=0.57, P \leq 0.0001)$, indicating that microsatellite markers are reliable tools in most cases to assess the genetic relationships among SHB cultivars. Finally, seven Vaccinium species constitute the current genetic base of cultivated SHB. In this article, we report on the expected genetic contributions of $V$. angustifolium Ait., V. constablaei Gray, V. corymbosum, V. darrowii Camp, V. elliottii Chapman, V. tenellum Ait., and $V$. virgatum Ait. (syn. $V$. ashei Reade) clones to $38 \mathrm{SHB}$ cultivars.
\end{abstract}

The blueberry is a recent major fruit crop to be brought under cultivation; improvement through breeding and selection did not begin until 1909 (Coville, 1937). The primary gene pool of blueberry consists of three species, highbush blueberry [ $\mathrm{Vacci}$ nium corymbosum $(2 \mathrm{n}=4 \mathrm{x}=48)]$, lowbush blueberry [ $V$. angustifolium $(2 \mathrm{n}=4 \mathrm{x}=48)]$, and rabbiteye blueberry [ $V$. virgatum $(2 \mathrm{n}=6 \mathrm{x}=72)]$, whereas the remaining noncultivated Cyanococcus species constitute the secondary gene pool (Lyrene and Ballington, 1986). During 100 years of blueberry improvement, homoploid and heteroploid interspecific hybridizations have been used extensively to combine useful traits found in the primary gene pool and to incorporate novel traits from wild germplasm. Wide hybridization reached its height

Received for publication 14 Dec. 2007. Accepted for publication 5 Mar. 2008. ${ }^{1}$ Current address: Reiter Affiliated Companies, 730 South A Street, Oxnard, CA 93030.

${ }^{2}$ Corresponding author. E-mail: brevis@msu.edu. during the development of "southern" highbush blueberry cultivars, which began in 1948 at the University of Florida (Sharpe, 1953). Southern highbush blueberries (SHB) are lowchill (less than $600 \mathrm{~h}$ below $7^{\circ} \mathrm{C}$ ) interspecific hybrids derived from highbush blueberry, lowbush blueberry, rabbiteye blueberry, and wild diploid species native to the southeastern United States (Ballington, 1990; Draper, 1997; Lyrene and Ballington, 1986; Sharpe and Darrow, 1959); the use of wild germplasm resulted in the incorporation of traits such as low chilling, tolerance to heat, drought and mineral soils, and disease resistance that helped to expand the geographic limits of highbush blueberry production. Unexpectedly, wild germplasm also improved fruit quality traits such as picking scar, firmness, color, and flavor (Draper, 1997). Although highbush blueberry breeding has been reviewed multiple times, it has been difficult to assess the genetic contributions of wild germplasm to SHB cultivars, because: 1) complete pedigrees (particularly those of newest cultivars) are not always available 
in the literature; 2) pedigree records generally mention Vaccinium taxa that are no longer valid; and 3) many SHB cultivars have unknown ancestors as a result of random selection of parents that go unreported or deliberate open-pollination.

Despite the important role of wide hybridization in blueberry breeding, we know little about its effects on DNA polymorphism. SHB are assumed to be highly heterozygous because of their broad genetic base (Lyrene, 2002); however, the hypothesis that wide hybridization has increased the levels of heterozygosity in cultivated highbush blueberry should be tested using a molecular approach. The objectives of this study were: 1) to report the expected genetic contribution of the Vaccinium species that constituted the current genetic base of cultivated SHB; 2) to establish the usefulness of microsatellite markers in assessing genetic relationships among SHB cultivars; and 3) to estimate the impact of wide hybridization on genetic relatedness and heterozygosity of highbush blueberry.

\section{Materials and Methods}

Pedigree information. Pedigrees of 107 tetraploid highbush blueberry cultivars released from seven public agencies in the United States were collected from published sources (Brooks and Olmo, 1997; Clark and Finn, 2006; Coville, 1937; Darrow et al., 1954; Draper et al., 1982; Ehlenfeldt, 1997; Hancock et al., 1995; Lyrene and Sherman, 2000; Lyrene et al., 1997; Moore, 1989; Okie, 1999, 2002, 2004; Rooks et al., 1995; Sharpe and Sherman, 1976; Spiers et al., 2002), breeding records, and direct communication with blueberry breeders (P.M. Lyrene and S.J. Stringer, personal communications). All crosses were entered into an Access database (version 2003; Microsoft Corp., Redmond, WA). Peditree, a software developed to query pedigree databases in Access format (van Berloo and Hutten, 2005), was used to construct tree-shaped representations of complete pedigrees, search for descendants of cultivars or selections of interest, and determine the number of cycles of selection. Cycles of selection were defined as the number of generations separating a cultivar from the farthest founding $V$. corymbosum clones. Cultivars were classified as SHB if at least one Vaccinium species native to the southeastern United States appeared in their ancestry. This broad definition, which does not take into account chilling requirement, was adopted to investigate the use of low chill wild germplasm beyond the boundaries of a particular growing region. Northern highbush blueberries (NHB) were classified as "historical" if they represented one to four cycles of selection and "modern" if they represented five to seven. Historical NHB, as defined previously, were introduced primarily from the 1920s through the 1960s.

EXPECTED GENETIC CONTRIBUtion. The expected genetic contribution of a clone or species to a cultivar was calculated as described by Sjulin and Dale (1987):

$$
G C=\sum_{1}^{x}(1 / 2)^{n}
$$

where $G C$ is the expected genetic contribution of a wild clone or group of clones from the same species, $n=$ number of generations in a pedigree pathway between the clone and the cultivar, and $x=$ number of pathways between the clone(s) and the cultivar. According to Eq. [1], expected parental contributions are 0.5 for an $F_{1}$ individual and either of its parents; the assumption of equal contributions from both parents is always adopted in pedigree-based studies (e.g., Bernardo et al., 2000; Enoki et al., 2002; Liu et al., 2003; Sjulin and Dale, 1987), although deviations between observed and expected parental contributions are known to occur (Bernardo et al., 1997).

Expected genetic contributions were adjusted when parents involved in the cross had different ploidy levels. We assumed that: 1) most hexaploid $\times$ diploid crosses produced pentaploid individuals with a genetic composition of $60 \%$ hexaploid parent to $40 \%$ diploid parent (Draper, 1997); 2) the selection US-17 (hexaploid $\times$ diploid) is an exception to the preceding rule, because it was known to be tetraploid (Darrow et al., 1954); its genetic composition was assumed to be 75\% 'Callaway' (hexaploid) to $25 \% \mathrm{~V}$. tenellum (diploid); and 3) tetraploid $\times$ $V$. darrowii (diploid) crosses produced tetraploid individuals with a 50\% contribution from each parent (Draper and Hancock, 2003).

Tetrasomic InBreeding CoefFicient. The inbreeding coefficient $(F)$ of autotetraploid highbush blueberry cultivars was calculated according to Loiselle et al. (1989) as the probability of a random pair from the four alleles at a locus being identical by descent:

$$
F_{X}=1 / 6\left(F_{y}+F_{z}+4 R_{y z}\right)
$$

where $F_{x}$ is the tetrasomic inbreeding coefficient of the genotypes of the full-sib family derived from the cross between parents $\mathrm{Y}$ and $\mathrm{Z} ; F_{y}$ and $F_{z}$ are the inbreeding coefficients of the parents; and

$$
R_{y z}=\sum\left\{(1 / 4)^{n_{1}+n_{2}+1}\left[1+3 F_{A}\right]\right\}
$$

where $R_{y z}$ is the relationship coefficient between the parents obtained by the summation of the preceding formula over the paths of relationship for all common ancestors $\left(F_{A}\right)$. The terms $n_{1}$ and $n_{2}$ are the number of generations separating parents $\mathrm{Y}$ and $\mathrm{Z}$ from the common ancestor. Peditree was used to identify common ancestors and to determine $n_{1}$ and $n_{2}$. Eqs. [2] and [3] were calculated using Excel 2003 (Microsoft Corp.). All parents were treated as tetraploid, and ancestors of unknown origin (e.g., founding clones) were assumed to be unrelated and noninbred. Cultivars with unknown parents or grandparents were excluded from calculations (six SHB cultivars: 'Avonblue', 'Emerald', 'Flordablue', 'Misty', 'Santa Fe', and 'Sunshine Blue'; five NHB cultivars: 'Aurora', 'Brigitta Blue', 'Caroline Blue', 'Denise Blue', and 'Liberty').

Coancestry Coefficient. Coancestry is the degree of relationship by descent between two individuals and is equivalent to the inbreeding coefficient of their progeny if they were mated (Falconer and Mackay, 1996). Coancestry coefficients for autotetraploid highbush blueberry were calculated using a program that assumes disomic inheritance given the limitation that no software has been specifically developed for autotetraploid crops. In a preliminary test, the tetrasomic inbreeding coefficient of $29 \mathrm{NHB}$ cultivars was significantly correlated with the disomic coancestry coefficient between their parents $(r=0.75 ; P \leq 0.0001)$. Coancestry coefficients for pairwise comparisons within historical NHB, modern NHB, and SHB were calculated using the software KIN (Tinker and Mather, 1993) assuming $\mathrm{S}=0$ as the inbreeding method (no selfpollination; the degree of inbreeding was determined from the pedigree). Only cultivars with well-documented pedigrees 
(genetic composition $12.5 \%$ or less unknown) were considered for this analysis (38 historical NHB, 23 modern NHB, and 35 SHB).

Pedigree-based Clustering analysis. Pedigree-based genetic distances among SHB cultivars were calculated by subtracting disomic coancestry coefficients from one. Then the software PowerMarker (version 3.25; Liu and Muse, 2005) was used to cluster cultivars based on genetic distances by the neighbor joining method. The output dendrogram was generated and edited using MEGA (version 4; Tamura et al., 2007). Three NHB genotypes that were extensively used in SHB cultivar development (Earliblue, Bluecrop, and Berkeley) were also included in the clustering analysis.

Simple SEQUenCe REPEAT GENOTYPING. Plant materials sampled included 51 cultivars held at the U.S. Department of Agriculture-Agricultural Research Service (USDA-ARS) National Clonal Germplasm Repository in Corvallis, OR; 13 cultivars obtained from Fall Creek Farm and Nursery in Lowell, OR; three cultivars obtained from the Michigan Blueberry Growers Association in Grand Junction, MI; and one selection held at the North Carolina State University blueberry breeding program in Raleigh. In total, 68 genotypes were sampled: 27 SHB cultivars (Avonblue, Biloxi, Bladen, Blue Ridge, Cape Fear, Cara's Choice, Craven, Draper, Emerald, Flordablue, Georgiagem, Jewel, Jubilee, Legacy, Magnolia, Millennia, Misty, O’Neal, Ozarkblue, Reveille, Santa Fe, Sapphire, Sebring, Sharpblue, Sierra, Southmoon, and Star), 20 NHB-historical cultivars [1613-A (Hardyblue), Atlantic, Berkeley, Bluecrop, Bluejay, Blueray, Cabot, Coville, Earliblue, Herbert, Ivanhoe, Jersey, June, Northland, Olympia, Pioneer, Rancocas, Stanley, Wareham, and Weymouth], 16 NHB-modern cultivars (Aurora, Bluetta, Bounty, Chandler, Chanticleer, Darrow, Duke, Elliott, Hannah's Choice, Liberty, Meader, Nui, Patriot, Spartan, Sunrise, and Toro), four wild $V$. corymbosum clones (Ashworth, Grover, Harding, and Rubel), and one numbered selection (US-75).

DNA was extracted in duplicate from actively growing young leaves using a modified large throughput protocol based on the PUREGENE ${ }^{\circledR}$ kit (Gentra Systems, Minneapolis, MN; detailed protocol provided on request from the author). The microsatellite or simple sequence repeat (SSR) markers used in this study were derived from expressed sequence tag libraries (16 primer pairs: CA23F, CA94F, CA112F, CA169F, CA190R, CA236F, CA344F, CA421F, CA483F, CA787F, CA794F, CA855F, NA41, NA398, NA961, and NA1040) and a microsatellite-enriched genomic library (five primer pairs: VCC I2, VCC I8, VCC J3, VCC J9, and VCC K4) constructed from NHB 'Bluecrop' DNA (Boches et al., 2005); these markers have been successfully used to amplify SSR loci across species of Vaccinium section Cyanococcus (Boches et al., 2006b). Polymerase chain reactions (PCRs) were carried out separately for each primer pair and up to three PCR products (one per SSR primer set) were pooled in a multiplex and separated using capillary electrophoresis.

PCR reactions were performed in $15 \mu \mathrm{L}$ volume containing $1 \times$ reaction buffer, $2 \mathrm{~mm} \mathrm{MgCl}_{2}, 0.2 \mathrm{~mm}$ dNTPs, $0.3 \mu \mathrm{M}$ of each primer (fluorescently labeled forward primer and an unlabeled reverse primer), 0.375 units of Biolase Taq DNA polymerase (Bioline USA, Taunton, MA), and $4.5 \mathrm{ng}$ of genomic DNA. The PCR protocol consisted of an initial denaturation at $94{ }^{\circ} \mathrm{C}$ for 3 min, 35 cycles in an Eppendorf Gradient thermocycler (Eppendorf North America, Westbury, NY), or an MJ Research Tetrad thermocycler (MJ Research, Waltham, MA) programmed for a 40-s denaturation step at $94{ }^{\circ} \mathrm{C}$, a 40 -s annealing step at the optimum annealing temperature of the primer pair (Boches et al., 2005), and a 40-s extension step at $72^{\circ} \mathrm{C}$. A final extension step was included at $72^{\circ} \mathrm{C}$ for $30 \mathrm{~min}$. The success of the PCR reaction was verified by agarose $(2 \%)$ gel electrophoresis before separation by capillary electrophoresis. The forward primers for CA23F, CA112F, CA169F, and NA398 were fluorescently labeled with FAM, HEX, or NED and the resulting PCR products were separated by capillary electrophoresis using an ABI 3100 capillary sequencer (Applied Biosystems, Foster City, CA) at the Central Services Laboratory (Oregon State University, Corvallis, OR). GeneScan (version 2.1; Applied Biosystems) and Genotyper (version 2.0; Applied Biosystems) were used for automated data collection and computation of allele size and accurate visualization of the alleles. The forward primers of the remaining SSRs were fluorescently labeled with WellRED (Beckman Coulter, Fullerton, CA) and the amplification products were analyzed using a CEQ 8000 genetic analyzer (Beckman Coulter). Allele sizing and visualization were performed using the fragment analysis module of the CEQ 8000 software (Beckman Coulter).

SIMPLE SEQUENCE REPEAT MARKER DATA ANALYSIS. SSR-based genetic distances between cultivars were computed using PowerMarker with the proportion of shared alleles distance $\left(\mathrm{D}_{\mathrm{sa}}\right)$ :

$$
D_{s a}=\frac{1}{m} \sum_{j=1}^{m} \sum_{i=1}^{a_{j}} \min \left(p_{i j}, q_{i j}\right)
$$

where $p_{i j}$ and $q_{i j}$ are the frequencies of the $i$ th allele at the $j$ th locus, $m$ is the number of loci examined, and $a_{j}$ is the number of alleles at the $j$ th locus. Each allele was treated as a separate locus in this analysis because allele dosage could not be inferred from SSR fingerprints of tetraploid individuals. Therefore, SSR data were transformed into a binary data matrix before analysis with " 1 " indicating the presence and " 0 " the absence of an allele.

To determine the usefulness of SSR markers in assessing genetic relationships, a correlation analysis was performed using SSR- and pedigree-based genetic distances among 18 fingerprinted SHB cultivars that have well-documented pedigrees (genetic composition $12.5 \%$ or less unknown). $D_{s a}$ and pedigree-based distances were calculated for all pairwise comparisons excluding cultivars with themselves and reciprocals. The Pearson's correlation coefficient was calculated using SAS PROC CORR (SAS Institute, Cary, NC).

SHB cultivars were clustered based on proportion of shared alleles distances using the same software and methods described previously for the pedigree-based clustering analysis.

Finally, the heterozygosity of a cultivar was defined as the average number of SSR alleles per locus. Given that SSR primer pairs amplified up to four alleles per individual, it was assumed that they correspond to a single locus. Therefore, the heterozygosity of a cultivar was calculated dividing the total number of amplified alleles by 21 loci.

\section{Results and Discussion}

Current Genetic base of CUltivated SOUThern Highbush BLUEBERRY. The taxonomy of Vaccinium section Cyanococcus is unclear with the number of species ranging from 24 (Camp, 
1945) to 9 (Vander Kloet, 1988) depending on the philosophy of the taxonomist. In this study, we adhered to Weakley (2007) in his notion that Vander Kloet's concept of $V$. corymbosum is too broad, resulting "in the taxonomic homogenization of the diversity of the group." For instance, Vander Kloet (1988) included $V$. elliottii in $V$. corymbosum, whereas allozyme and SSR marker data support the recognition of both taxa as distinct species (Boches et al., 2006b; Bruederle and Vorsa, 1994). Therefore, in this study, we followed Weakley (2007) by recognizing $V$. constablaei, $V$. elliottii, and $V$. virgatum as valid species. However, Weakley also introduced a controversial idea, which is that $V$. corymbosum germplasm has played a secondary role in cultivar development and that $V$. formosum Andrews (syn. $V$. australe Small, sensu Camp) is the species with the largest contribution to the genetic base of cultivated highbush blueberry. Because $V$. corymbosum is broadly recognized as the primary source of germplasm in the cultivated highbush blueberry (Luby et al., 1991; U.S. Department of Agriculture, 2007), we used a species list that compromises between the taxonomic philosophies of Weakley and Vander Kloet (Table 1). According to this treatment, seven species now constitute the genetic base of cultivated SHB. Blueberry breeders from public agencies have also hybridized highbush blueberry with three additional species, $V$. myrsinites Lamarck, $V$. pallidum Ait., and $V$. simulatum Small, which may eventually be incorporated into the genetic background of named SHB cultivars (Ballington et al., 2006).

EXPECTED GENETIC CONTRIBUTIONS OF SPECIES AND CLONES. Vaccinium darrowii is present in the ancestry of 37 of 38 SHB cultivars (Table 2). The sources of germplasm were Florida 4B, FL 4A, clone "D," and Florida 9A. In many instances, pedigree records do not specify clone names, so the contribution of additional clones such as Florida 6A and Florida 34 may have gone unreported. The average genetic contribution of $V$. darrowii to $\mathrm{SHB}$ is $\approx 15 \%$ (overall average across 38 cultivars). 'Biloxi', 'Sharpblue', 'Palmetto', and 'Jubilee' are, in that order, the cultivars with the highest proportion of $V$. darrowii, ranging from $27 \%$ to $33 \%$.

Vaccinium virgatum is present in the ancestry of 24 SHB cultivars. The sources of germplasm were 'Black Giant', 'Myers', “A\#1”, 'Ethel' (also known as 'Satilla'), 'Walker', and "\#3". The average genetic contribution of $V$. virgatum to $\mathrm{SHB}$ is $\approx 5 \%$. 'Flordablue', 'Sharpblue', 'Cara's Choice', 'Sierra', and 'Biloxi' are the cultivars with the highest proportion of $V$. virgatum, ranging from $11 \%$ to $15 \%$.
Vaccinium tenellum is present in only eight cultivars and its expected genetic contribution ranges from $0.2 \%$ to $1.3 \%$. All contributions can be traced back to two interspecific hybrids selected from the cross $V$. virgatum 'Callaway' $\times V$. tenellum; these are the tetraploid US-17 and an unnamed pentaploid selection.

Vaccinium constablaei is present in the ancestry of 'Cara's Choice' and 'Sierra'. This species is native to the mountains of western North Carolina and eastern Tennessee and has been used in blueberry breeding to transfer late flowering and early ripening (Ballington et al., 1984; Ehlenfeldt, 1997). 'Cara's Choice' and 'Sierra' are cold-hardy and have a high chilling requirement (greater than $600 \mathrm{~h}$ below $7^{\circ} \mathrm{C}$ ), so their phenotype does not correspond to that of a "true" SHB. Nevertheless, for the purpose of this study, both cultivars were classified as SHB because of the presence of low chill species in their ancestry.

'Carteret' is unique among SHB because it is the only cultivar released to date that has $V$. elliottii in its genetic background; also, it is the only tetraploid SHB cultivar without any $V$. darrowii in its genetic background.

The average genetic contribution of Vaccinium angustifolium to SHB is $\approx 4 \%$. The sources of germplasm were 'Russell', which is one of Coville's (1937) founding clones, and also 'North Sedgewick' and 'Michigan Lowbush \#1'. The North Carolina cultivars Blue Ridge, Cape Fear, Sampson, and O'Neal have the highest proportion of $V$. angustifolium, ranging from $11 \%$ to $16 \%$.

The expected genetic contribution of $V$. corymbosum has declined from $97 \%$ in the original northern-adapted gene pool to $72 \%$ in the average SHB cultivar. The NHB genotypes most commonly used as parents during SHB cultivar development, followed by their number of SHB descendants, were: 'Earliblue' (27), 'Bluecrop' (23), 'Berkeley’ (16), US11-93 (16), F72 (14), and 'Dixi' (10).

GENETIC RELATIONSHIPS AMONG SOUTHERN HIGHBUSH BLUEBERRY BASED ON PEDIGREE AND SIMPLE SEQUENCE REPEAT MARKER DATA. SSR- and pedigree-based genetic distances between pairs of SHB cultivars were significantly correlated $(P \leq 0.0001)$, although the correlation coefficient was relatively small $(r=0.57)$. In general, relatedness measures based on pedigree data are expected to deviate to some extent from those based on molecular marker data because the former are dependent on assumptions that can be violated; e.g., allelic contributions from both parents are equal (i.e., no selection, mutation, or genetic drift), pedigree records are accurate, and

Table 1. Vaccinium section Cyanococcus species that constitute the current genetic base of cultivated southern highbush blueberry as recognized by most Vaccinium crop geneticists. ${ }^{\mathrm{z}}$

\begin{tabular}{|c|c|c|c|c|}
\hline \multirow[b]{2}{*}{ Species } & \multirow[b]{2}{*}{ Ploidy level } & \multicolumn{3}{|c|}{ Synonym } \\
\hline & & Camp (1945) & Vander Kloet (1988) & Weakley (2007) \\
\hline V. angustifolium Ait. & $4 \times$ & V. lamarckii Camp & V. angustifolium & V. angustifolium \\
\hline V. constablaei Gray & $6 \times$ & V. constablaei & V. corymbosum & V. constablaei \\
\hline & $4 \times$ & $\begin{array}{l}\text { V. australe Small, V. corymbosum, } \\
\text { V. fuscatum }\end{array}$ & V. corymbosum & $\begin{array}{l}V . \text { corymbosum, } V \text {. formosum } \\
\text { Andrews, } V \text {. fuscatum }\end{array}$ \\
\hline V. darrowii Camp & $2 \times$ & V. darrowii & V. darrowii & V. darrowii \\
\hline V. tenellum Ait. & $2 \times$ & V. tenellum & $V$. tenellum & V. tenellum \\
\hline V. virgatum Ait. & $6 \times$ & V. ashei Reade, $V$. amoenum Ait. & V. corymbosum & V. virgatum \\
\hline
\end{tabular}

${ }^{\mathrm{z}}$ Synonyms are given for comparison with taxa from three taxonomic treatments of the genus. 
Table 2. Expected genetic contribution of $V$. darrowii, V. virgatum, and other Vaccinium species to 38 southern highbush blueberry cultivars released by seven public agencies in the United States. ${ }^{\mathrm{z}}$

\begin{tabular}{|c|c|c|c|c|c|c|}
\hline \multirow[b]{3}{*}{ Cultivar name } & \multirow[b]{3}{*}{ Origin (cross) } & \multicolumn{2}{|l|}{ V. darrowii } & \multicolumn{2}{|c|}{ V. virgatum } & \multirow[b]{2}{*}{ Other species } \\
\hline & & Clone & Total & Clone & Total & \\
\hline & & \multicolumn{5}{|c|}{ - } \\
\hline \multicolumn{7}{|c|}{ Michigan State University } \\
\hline Draper $^{\mathrm{y}}$ & Duke $\times$ G-751 & Unspecified (1.6) & 1.6 & $\begin{array}{l}\text { Black Giant }(0.6) \\
\text { Myers }(0.6)\end{array}$ & 1.2 & $\begin{array}{l}\text { V. tenellum }(0.4), \\
\quad V . \text { angustifolium (6.0), } \\
\text { unknown }(6.3)\end{array}$ \\
\hline \multicolumn{7}{|c|}{ USDA-ARS (Beltsville, MD) and Rutgers University } \\
\hline Cara's Choice & G-144 × US-165 & Florida 4B (20.0) & 20.0 & $\begin{array}{l}\text { Black Giant (3.8) } \\
\text { Myers (3.8) } \\
\text { Walker (7.5) }\end{array}$ & 15.0 & $\begin{array}{l}\text { V. constablaei (15.0), } \\
\text { V. angustifolium (2.3) }\end{array}$ \\
\hline Legacy & Elizabeth $\times$ US-75 & Florida 4B (25.0) & 25.0 & & 0 & V. angustifolium (1.6) \\
\hline Sierra & US-169 × G-156 & Florida 4B (20.0) & 20.0 & $\begin{array}{l}\text { Black Giant (3.8) } \\
\text { Myers (3.8) } \\
\text { Walker (7.5) }\end{array}$ & 15.0 & $\begin{array}{l}\text { V. constablaei (15.0), } \\
\text { V. angustifolium (2.3) }\end{array}$ \\
\hline \multicolumn{7}{|c|}{ University of Arkansas } \\
\hline Ozarkblue & G-144 × Florida $4-76$ & $\begin{array}{l}\text { Florida 4B (5.0) } \\
\text { Clone D }(6.3)\end{array}$ & 11.3 & Clone A\#1 (7.5) & 7.5 & V. angustifolium (3.9) \\
\hline Summit & G-144 × Florida 4-76 & $\begin{array}{l}\text { Florida 4B }(5.0) \\
\text { Clone D }(6.3)\end{array}$ & 11.3 & Clone A\#1 (7.5) & 7.5 & V. angustifolium (3.9) \\
\hline \multicolumn{7}{|c|}{ North Carolina State University } \\
\hline Arlen & G-144 × Florida 4-76 & $\begin{array}{l}\text { Florida 4B (5.0) } \\
\text { Clone D }(6.3)\end{array}$ & 11.3 & Clone A\#1 (7.5) & 7.5 & V. angustifolium (3.9) \\
\hline Beaufort & NC $1406 \times$ Pender & Florida 4B (12.5) & 12.5 & & 0 & $V$. angustifolium (2.3) \\
\hline Bladen $^{y}$ & NC $1171 \times$ NC SF-12-L & Unspecified (3.1) & 3.1 & $\begin{array}{l}\text { Black Giant (1.2) } \\
\text { Myers (1.2) }\end{array}$ & 2.3 & $\begin{array}{l}\text { V. tenellum (0.8), } \\
\quad \text { V. angustifolium (4.1), } \\
\text { unknown (12.5) }\end{array}$ \\
\hline Blue Ridge & Patriot $\times$ US-74 & Florida 4B (25.0) & 25.0 & & 0 & V. angustifolium (15.6) \\
\hline Cape Fear & US-75 $\times$ Patriot & Florida 4B (25.0) & 25.0 & & 0 & V. angustifolium (15.6) \\
\hline Carteret & Bounty $\times$ NC 2426 & & 0 & & 0 & $\begin{array}{l}\text { V. elliottii }(25) \text {, } \\
\quad \text { V. angustifolium (3.5) }\end{array}$ \\
\hline Craven & NC $1406 \times$ Pender & Florida 4B (12.5) & 12.5 & & 0 & $V$. angustifolium (2.3) \\
\hline Duplin $^{y}$ & $290-1 \times$ G-156 & Uunspecified (3.1) & 3.1 & $\begin{array}{l}\text { Black Giant (1.2) } \\
\text { Myers (1.2) }\end{array}$ & 2.3 & $\begin{array}{l}\text { V. tenellum }(0.8), \\
\text { V. angustifolium (2.5), } \\
\text { unknown (12.5) }\end{array}$ \\
\hline Lenoir & NC $1406 \times$ Pender & Florida 4B (12.5) & 12.5 & & 0 & V. angustifolium (2.3) \\
\hline New Hanover & NC $1522 \times$ O’Neal & $\begin{array}{l}\text { Florida 4B (12.5) } \\
\text { Unspecified (1.3) }\end{array}$ & 13.8 & $\begin{array}{l}\text { Black Giant (0.9) } \\
\text { Myers }(0.9)\end{array}$ & 1.9 & V. angustifolium (6.1) \\
\hline O’Neal & Wolcott $\times$ Florida $64-15$ & Unspecified (2.5) & 2.5 & $\begin{array}{l}\text { Black Giant (1.9) } \\
\text { Myers (1.9) }\end{array}$ & 3.8 & V. angustifolium (10.5) \\
\hline Pamlico & NC $1406 \times$ Pender & Florida 4B (12.5) & 12.5 & & 0 & $V$. angustifolium (2.3) \\
\hline Reveille $^{\mathrm{y}}$ & NC $1171 \times$ NC SF-12-L & Unspecified (3.1) & 3.1 & $\begin{array}{l}\text { Black Giant (1.2) } \\
\text { Myers (1.2) }\end{array}$ & 2.3 & $\begin{array}{l}\text { V. tenellum }(0.8) \text {, } \\
\quad \text { V. angustifolium (4.1), } \\
\text { unknown (12.5) }\end{array}$ \\
\hline Sampson & Bluechip $\times$ NC 1524 & Florida 4B (12.5) & 12.5 & & 0 & V. angustifolium (10.9) \\
\hline Summit & G-144 × Florida 4-76 & $\begin{array}{l}\text { Florida 4B (5.0) } \\
\text { Clone D }(6.3)\end{array}$ & 11.3 & Clone A\#1 (7.5) & 7.5 & V. angustifolium (3.9) \\
\hline \multicolumn{7}{|c|}{ University of Georgia } \\
\hline Camellia $^{\mathrm{x}}$ & MS-122 × MS-6 & $\begin{array}{l}\text { Florida 4B (12.5) } \\
\text { Unspecified (7.2) }\end{array}$ & 19.7 & $\begin{array}{l}\text { Black Giant }(0.9) \\
\text { Ethel (1.9) } \\
\text { Myers }(0.9)\end{array}$ & 3.8 & $\begin{array}{l}V . \text { angustifolium (1.6), } \\
\text { unknown (3.1) }\end{array}$ \\
\hline Georgiagem & G-132 × US-75 & Florida 4B (25.0) & 25.0 & & 0 & V. angustifolium (3.9) \\
\hline Palmetto & US-158 × TH-157 & $\begin{array}{l}\text { Florida 4A (3.1) } \\
\text { Florida 4B (25.0) }\end{array}$ & 28.1 & & 0 & $\begin{array}{l}\text { V. angustifolium (1.8), } \\
\text { unknown (3.1) }\end{array}$ \\
\hline \multicolumn{7}{|c|}{ USDA-ARS (Poplarville, MS) } \\
\hline Biloxi $^{\mathrm{x}}$ & Sharpblue $\times$ US-299 & $\begin{array}{l}\text { Clone D (3.1) } \\
\text { Florida 4B (8.8) } \\
\text { Florida 9A (6.3) } \\
\text { Unspecified (14.4) }\end{array}$ & 32.5 & $\begin{array}{l}\text { Black Giant (1.9) } \\
\text { Clone A\#1 (3.8) } \\
\text { Ethel (3.8) } \\
\text { Myers (1.9) }\end{array}$ & 11.3 & $\begin{array}{l}\text { V. corymbosum } \\
\text { f. atrococcum } 2 \mathrm{x}(6.3) \\
\text { V. angustifolium }(1.8), \\
\text { unknown (6.3) } \\
\text { continued next page }\end{array}$ \\
\hline
\end{tabular}




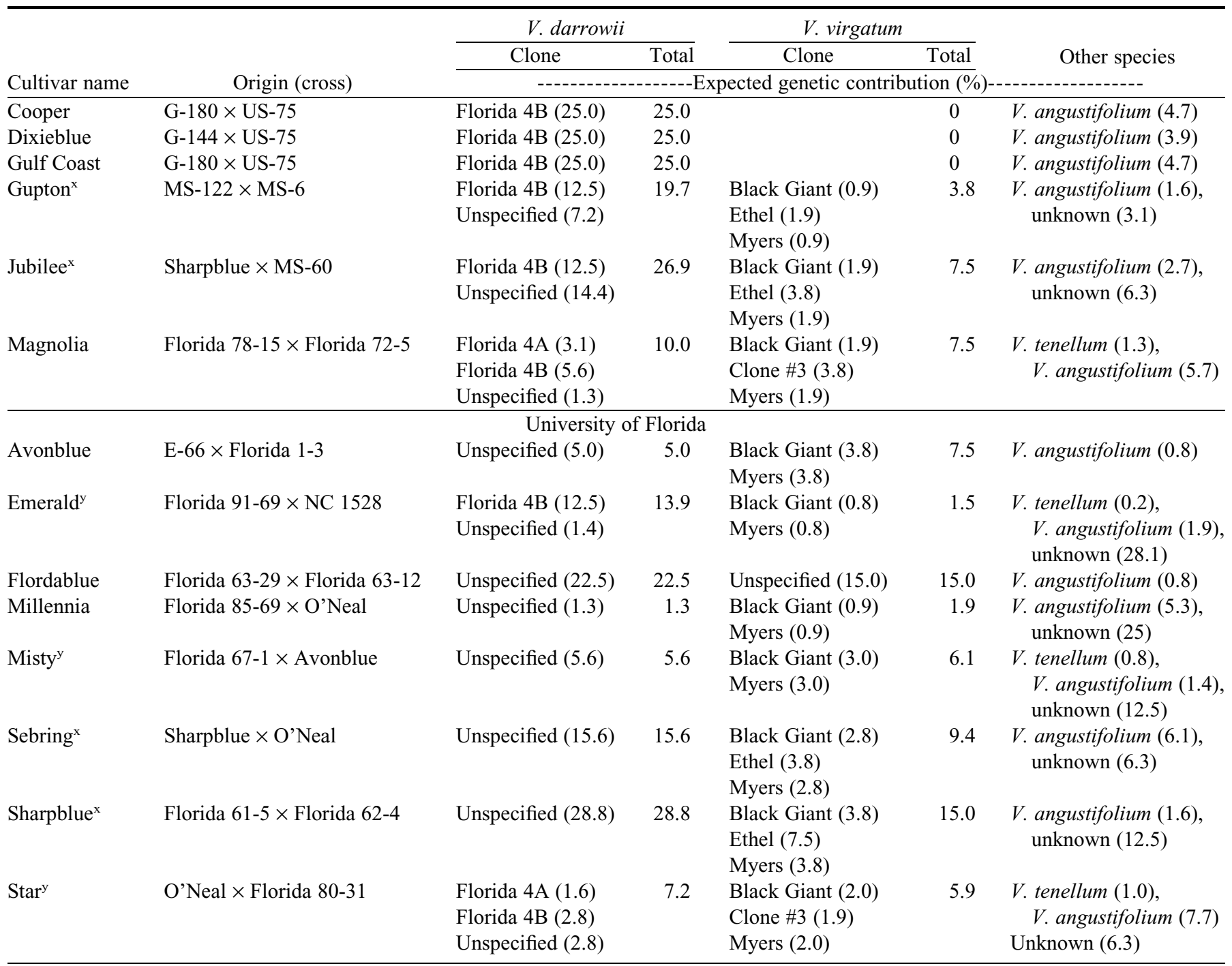

${ }^{z}$ The percentage of $V$. corymbosum is not shown but can be calculated subtracting all listed contributions from $100 \%$.

'It was assumed that Florida 61-7 is a descendant of 'Earliblue'.

${ }^{x}$ It was assumed that Florida 62-4 is a descendant of E-30.

founding clones are unrelated (Liu et al., 2003). Previous studies in maize have shown significant $(P \leq 0.05)$ correlations between SSR- and pedigree-based relatedness measures (Bernardo et al., 2000; Enoki et al., 2002; Liu et al., 2003; Pejic et al., 1998; Smith et al., 1997); the magnitude of the correlation coefficients reported in these studies appears to be related to the number of SSR markers used. Although Bernardo et al. (2000) obtained the highest correlation coefficient $(r=0.92)$ using 195 primer pairs, Pejic et al. (1998) obtained the lowest $(r=0.53)$ using 27 primer pairs. The relatively low correlation coefficient obtained in this study may be explained by: 1) the low number of SSR markers used (21 primer pairs); 2) the high proportion of dinucleotide repeat SSRs (12 markers or 57\%), which tend to have higher mutation rates than SSRs with longer repeat motifs (Liu et al., 2003); or 3) the use of pedigree distances based on disomic inheritance.

A dendrogram was constructed to show genetic relationships based on pedigree data (Fig. 1). The largest clade grouped $V$. darrowii Florida 4B backcross derivatives to $V$. corymbosum with 'Bluecrop' as the common NHB parent. These cultivars are primarily $\mathrm{BC}_{1}$ ('Blue Ridge', 'Cape Fear', 'Cooper', 'Dixieblue', 'Georgiagem', 'Gulf Coast', and 'Legacy') and $\mathrm{BC}_{2}$ ('Sampson'). The three remaining SHB cultivars in this group (full-sibs 'Arlen', 'Ozarkblue', and 'Summit') have $V$. virgatum in their genetic background in addition to $V$. darrowii. Cultivars from this clade were developed for a variety of growing areas, ranging from New Jersey to Mississippi (USDA plant hardiness zones 6 to 8 , respectively).

'Sharpblue' clustered with its progeny 'Biloxi', 'Jubilee', and 'Sebring'. All four cultivars are low chill blueberries developed for USDA plant hardiness zone 8 . The pedigree of these cultivars is fairly complex; e.g., 'Biloxi' contains five $\mathrm{F}_{1} \mathrm{~S}$ from $V$. corymbosum and $V$. darrowii and two $\mathrm{F}_{1} \mathrm{~s}$ from $V$. darrowii and $V$. virgatum. Approximately $40 \%$ of the genetic composition of these cultivars is expected to come from the low chill species $V$. darrowii, $V$. virgatum, and $V$. tenellum.

'O'Neal' clustered with its progeny 'Star' and 'New Hanover'. These cultivars have a relatively high proportion of 


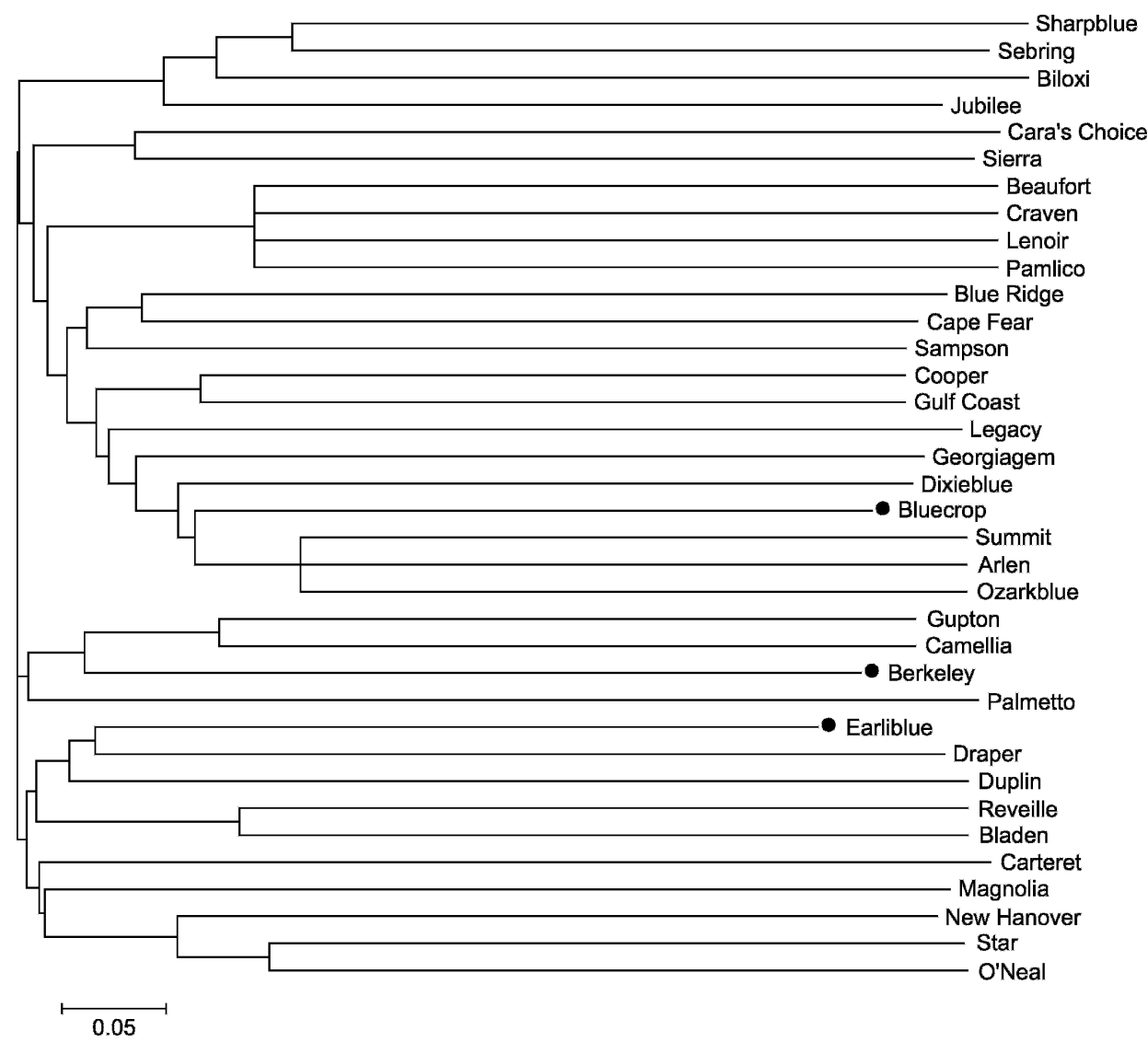

Fig. 1. Neighbor joining dendrogram of southern highbush blueberry cultivars based on genetic distance (1coancestry) calculated from pedigree data. Three northern highbush blueberry cultivars included in this analysis are labeled with a solid dot.

$V$. angustifolium in their ancestry (greater than 6\%) with clone 'North Sedgewick' as the main contributor.

'Camellia', 'Gupton', 'Draper', and 'Duplin' clustered with either 'Berkeley' or 'Earliblue', reflecting the fact that one of these two NHB was frequently used as recurrent parent. 'Camellia' and 'Gupton' are full-sibs. 'Draper' and 'Duplin' have a high proportion of $V$. corymbosum 'Ashworth' in their ancestry (18.8\% and $25.0 \%$, respectively).

Full-sibs 'Bladen' and 'Reveille' clustered together. Approximately $13 \%$ of their genetic composition is expected to come from 'Crabbe-4', a wild $V$. corymbosum clone that is not present in the ancestry of NHB cultivars released by Coville (1937).

Several cultivars were distantly related to other SHB primarily because of the contributions from "rare" wild clones. An unnamed $V$. constablaei clone is present in 'Cara's Choice' and 'Sierra'. $V$. corymbosum B-1 is present in full-sibs 'Beaufort', 'Craven', 'Lenoir', and 'Pamlico'. Also, V. elliottii E4-2 is present in 'Carteret'.

Dendrograms constructed from pedigree data (Fig. 1) and $D_{s a}$ (Fig. 2) exhibited many similarities. For instance: 1) 'Blue Ridge', 'Cape Fear', 'Legacy', 'Ozarkblue', and 'Georgiagem' were grouped in the same clade as 'Bluecrop'; 2) 'Biloxi', 'Jubilee', and 'Sebring' clustered with their parent 'Sharpblue'; and 3) full-sibs 'Bladen' and 'Reveille' clustered with each other and showed a loose association with other SHB.

Several cultivars were not included in the pedigree-based clustering analysis because of their incomplete pedigree records. In the case of 'Flordablue', its species composition is expected to be very similar to that of 'Sharpblue' (Table 2), so it was not surprising that both cultivars were grouped in the same clade (Fig. 2). 'Sapphire', whose pedigree is unknown, is likely to be progeny of 'Sharpblue' given the close genetic distance between them $\left(D_{s a}=\right.$ 0.167). Additionally, 'Jewel' and 'Southmoon' are likely to have inherited common SSR alleles from low chill ancestors ( $V$. darrowii or V. virgatum).

'Avonblue' clustered with its progeny 'Misty' and 'Santa Fe' and its descendant 'Emerald'. 'Millennia', whose pedigree is incomplete, is likely to be a descendant of 'Avonblue' given its location on the dendrogram. The association between 'Berkeley' and the rest of the clade may be explained by the fact that $25 \%$ of the ancestry of 'Avonblue' is 'Berkeley'.

'Cara's Choice' and 'Sierra' were separated by a large SSR distance $\left(D_{s a}=0.249\right)$ despite their high degree of coancestry (Fig. 1); furthermore, these cultivars shared more alleles with their NHB ancestors 'Bluecrop' and 'Earliblue' than with each other (Fig. 3) despite that the genetic contribution of $V$. corymbosum to 'Cara's Choice' and 'Sierra' is expected to be low (48\%; Table 2). These results suggest that selection under New Jersey conditions could have favored the highbush parent and that the pedigree data would overestimate the actual proportion of the genome derived from low chill species.

'Craven', 'Draper', and 'Magnolia' clustered with each other despite their low degree of coancestry. 'Draper' and 'Magnolia' have selection E-22 as a common ancestor, which is a 'North Sedgewick' $\mathrm{BC}_{1}$ derivative to $V$. corymbosum. Similarly, 'Craven' and 'Magnolia' have selection F-6 as a common ancestor, which is an $\mathrm{F}_{1}$ from 'Crabbe-4' and cultivated NHB. It may be possible that rare alleles from 'North Sedgewick' and 'Crabbe-4', which have not been transferred to other SHB cultivars included in this study, are responsible for the close shared allele distances among 'Craven', 'Draper', and 'Magnolia'.

Finally, 'Star' did not cluster with its parent 'O'Neal', and instead, exhibited a closer shared allele distance to 'Avonblue's' clade. These results suggest that selection under Florida conditions could have favored alleles from low chill ancestors over those from $V$. angustifolium.

In summary, pedigree and SSR distances were significantly correlated, and dendrograms constructed from either data set exhibited many similarities. SSRs were, in most cases, a reliable tool to assess the genetic relationships among SHB cultivars.

Pedigree and Simple Sequence repeat-based genetic DISTANCES AMONG NORTHERN HIGHBUSH BLUEBERRY AND SOUTHERN HIGHBUSH BLUEBERRY CULTIVARS. Distributions of 


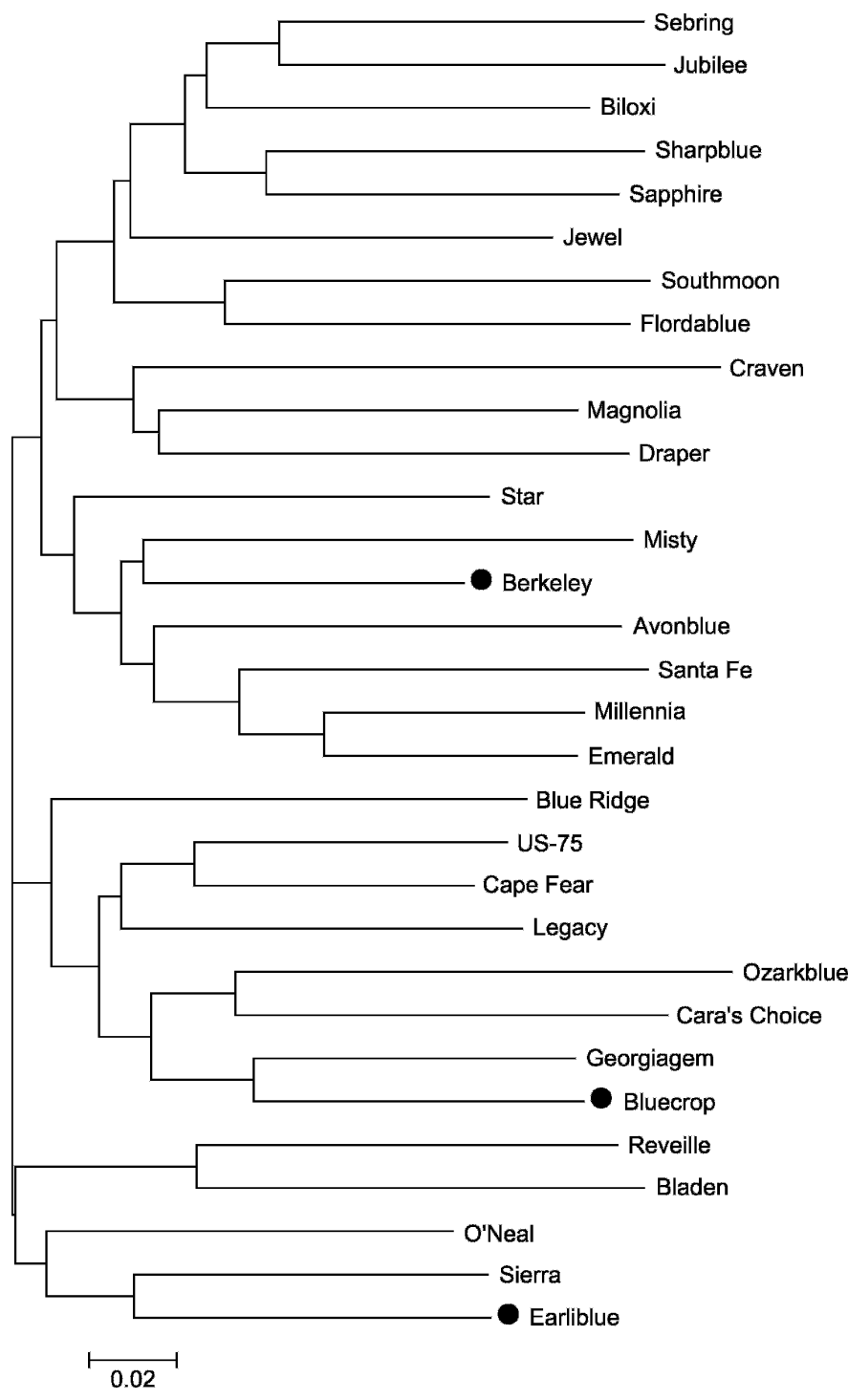

Fig. 2. Neighbor joining dendrogram of southern highbush blueberry cultivars based on shared allele distances. Three northern highbush blueberry cultivars included in this analysis are labeled with a solid dot.

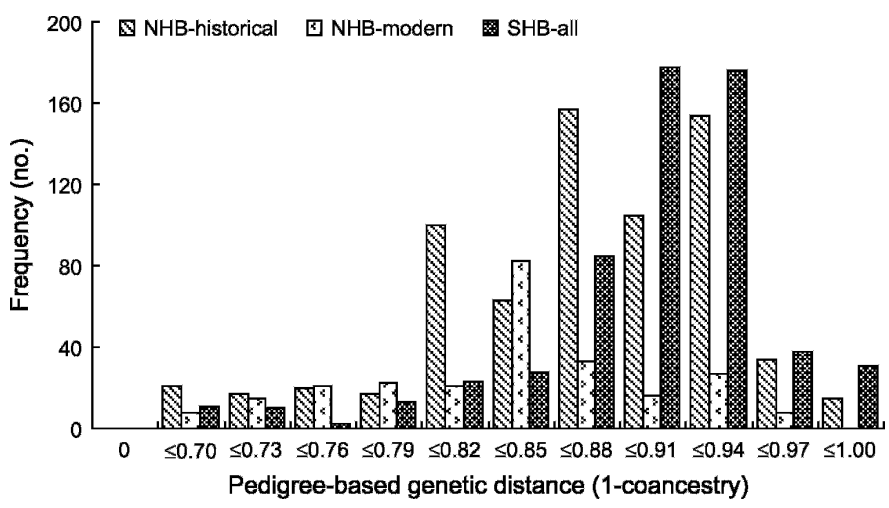

Fig. 3. Distributions of pedigree-based genetic distances among northern highbush blueberry (NHB) and southern highbush blueberry (SHB) cultivars. Genetic distances were calculated for all pairwise comparisons, excluding cultivars with themselves and reciprocals. NHB cultivars were considered "historical" if they had one to four cycles of selection and "modern" if they had five to seven. Sample sizes (number of cultivars) were as follows: NHBhistorical $=38 ;$ NHB-modern $=23 ;$ SHB $=35$. pedigree-based genetic distances between pairs of highbush blueberry cultivars are shown in Figure 3. According to pedigree data, SHB cultivars were more distantly related to each other than NHB cultivars to each other. Median genetic distances among SHB, NHB-historical, and NHB-modern cultivars were $0.90,0.88$, and 0.83 , respectively.

Distributions of shared allele distances between pairs of highbush blueberry cultivars are shown in Figure 4. Genetic distances calculated from pedigree and SSR marker data followed a similar pattern, although $\mathrm{D}_{\mathrm{sa}}$ among SHB were not higher than those among NHB-historical. Median $\mathrm{D}_{\mathrm{sa}}$ among SHB, NHB-historical, and NHB-modern were $0.19,0.19$, and 0.17 , respectively.

INBREEDING COEFFICIENT AND HETEROZYGOSITY OF NORTHERN HIGHBUSH BLUEBERRY AND SOUTHERN HIGHBUSH BLUEBERRY CULTIVARS. The tetrasomic inbreeding coefficient $(F)$ was significantly correlated to heterozygosity in NHB $(r=-0.41$; $\mathrm{n}=34 ; P \leq 0.05)$; as expected, heterozygosity tended to decrease with increasing levels of inbreeding. However, the magnitude of the Pearson's correlation coefficient was low, indicating that heterozygosity can vary greatly among cultivars with the same level of inbreeding. In SHB, $F$ and heterozygosity were not correlated $(r=0.13 ; \mathrm{n}=19 ; P>0.05)$.

NHB-modern cultivars are more inbred than either the NHB-historical or SHB genotypes (Fig. 5). Median inbreeding coefficients for SHB, NHB-historical, and NHB-modern cultivars were $0.0013,0.0013$, and 0.0035 , respectively.

The distributions of loci in wild $V$. corymbosum clones and NHB-historical cultivars were not statistically different $\left(\chi^{2}=\right.$ $0.5 ; \mathrm{df}=3 ; P>0.05$ ) (Fig. 6). NHB-historical and NHBmodern exhibited different loci distributions $\left(\chi^{2}=19.7 ; \mathrm{df}=3\right.$; $P \leq 0.001)$, with the first being more heterozygous than the latter. In NHB-modern, the frequency of quadriallelic loci (with four different alleles) was significantly reduced relative to NHB-historical, which has resulted in an increase in the frequency of loci with one and two alleles.

NHB-historical and SHB exhibited different loci distributions $\left(\chi^{2}=13.6 ; \mathrm{df}=3 ; P \leq 0.01\right)$ with the first being more heterozygous than the latter. Additionally, SHB and NHBmodern exhibited similar loci distribution $\left(\chi^{2}=4.0 ; \mathrm{df}=3\right.$; $P>0.05)$, despite NHB-modern being on average almost three times as inbred as SHB.

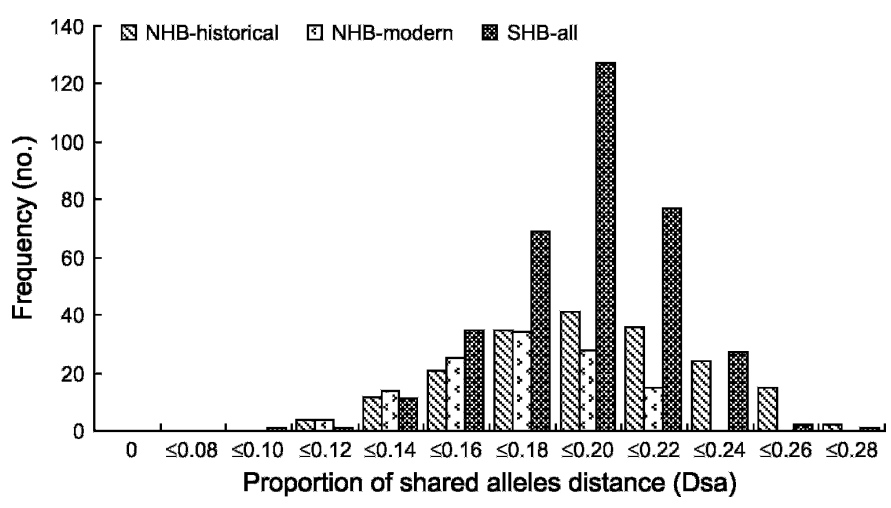

Fig. 4. Distributions of simple sequence repeat-based genetic distances among northern highbush blueberry (NHB) and southern highbush blueberry (SHB) cultivars. Genetic distances were calculated for all pairwise comparisons, excluding cultivars with themselves and reciprocals. Sample sizes (number of cultivars) were as follows: $\mathrm{NHB}$-historical $=20 ; \mathrm{NHB}-$ modern $=16 ; \mathrm{SHB}=27$. 


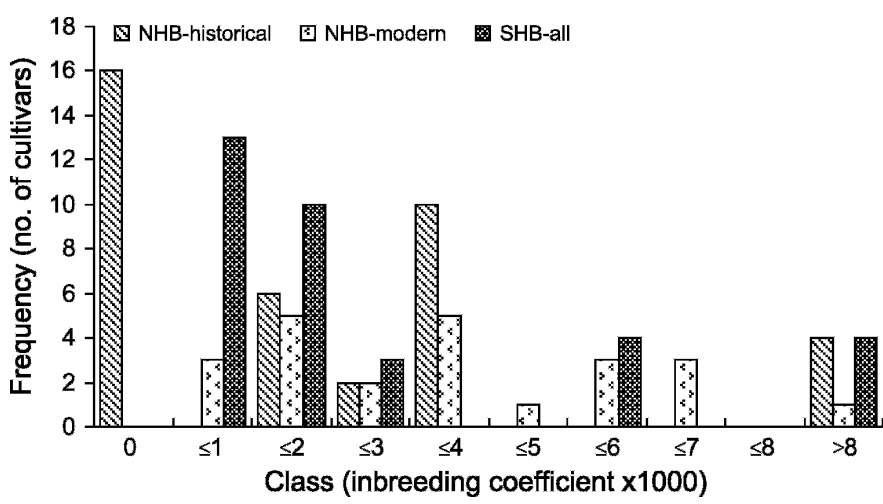

Fig. 5. Distributions of tetrasomic inbreeding coefficients of northern highbush blueberry (NHB) and southern highbush blueberry (SHB) cultivars.

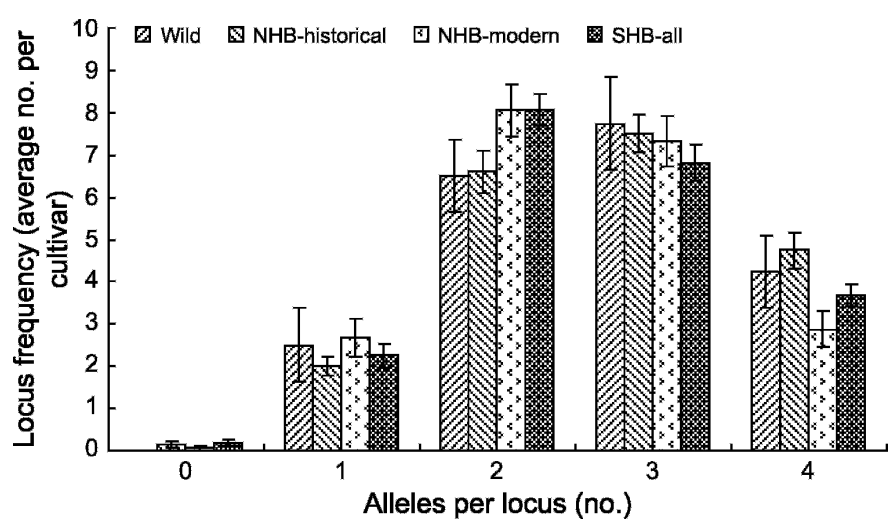

Fig. 6. Frequency distributions of loci according to their number of amplified alleles. Data came from 21 single-locus simple sequence repeat markers screened across wild northern highbush blueberry selections, historical and modern northern highbush blueberry (NHB) cultivars, and southern highbush blueberry (SHB) cultivars. Values are averages per cultivar, and bars represent SE. Sample sizes (number of cultivars) are as follows: wild $=4$; NHB-historical $=20 ;$ NHB-modern $=16 ; \mathrm{SHB}=27$.

NHB cultivars were noninbred up to two cycles of selection (Fig. 7). Then, $F$ increased considerably in the third generation because of hybridization within the limited genetic base of NHB. $F$ dropped considerably at six cycles of selection because of resampling of wild $V$. corymbosum germplasm; e.g., clone 'Ashworth' in cultivars such as 'Bluegold' and 'Nui' and clone B-1 in 'Pender'. However, $F$ increased to its highest level at seven cycles of selection. The general trend of increasing values of $F$ with increasing cycles of selection is consistent with previous reports (Ehlenfeldt, 1994; Hancock and Siefker, 1982). In SHB, $F$ and cycles of selection were not correlated $(r=-0.29 ; \mathrm{n}=19 ; P>0.05)$.

In NHB, heterozygosity and cycles of selection were negatively associated ( $P \leq 0.001$; Fig. 8$)$. Our fitted regression model predicts that NHB cultivars with one and seven cycles of selection have an average of 2.79 and 2.44 SSR alleles per locus, respectively; these estimates indicate that, after six cycles of selection, the heterozygosity of NHB cultivars had dropped $12 \%$. Selection targeted at individual loci will reduce genetic diversity within and around the selected loci (Halliburton, 2004). The negative association between heterozygosity and cycles of selection in NHB would indicate decreasing diversity throughout the genome as a consequence of selective

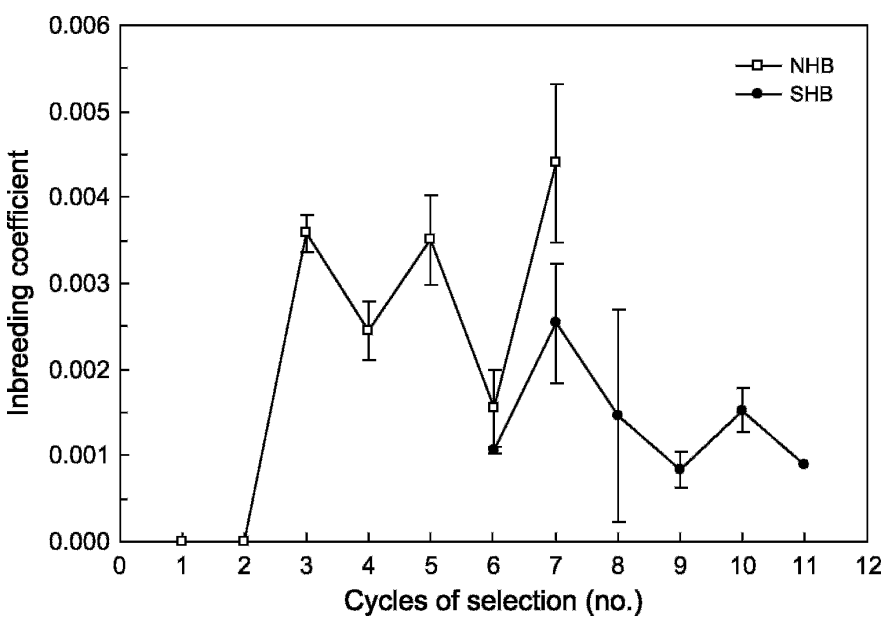

Fig. 7. Mean inbreeding coefficient of northern highbush blueberry (NHB) and southern highbush blueberry (SHB) cultivars plotted against the number of cycles of selections (i.e., generations separating the cultivar from the farthest founding Vaccinium corymbosum clones). Sample sizes (number of cultivars) were as follows: $\mathrm{NHB}=56 ; \mathrm{SHB}=30$. Cultivars with outlaying inbreeding coefficients $(>0.01)$ were excluded from the calculation of means (five NHB and four SHB). Bars represent SE.

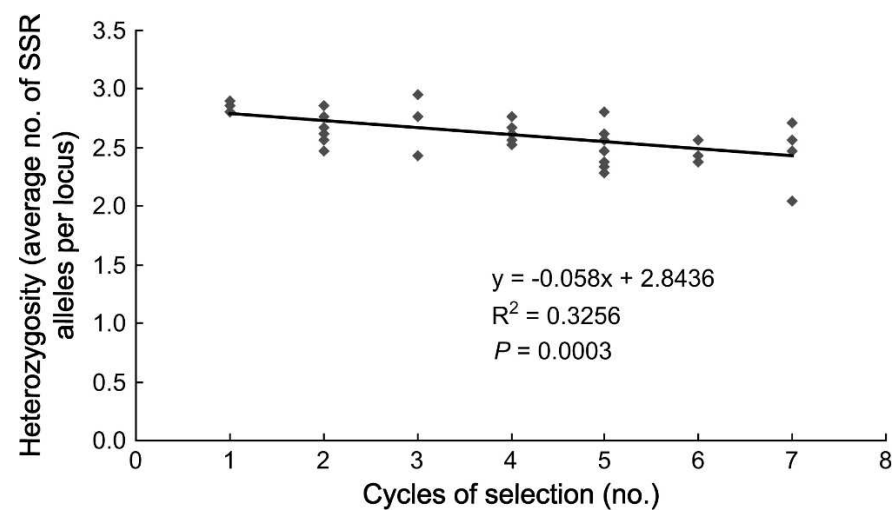

Fig. 8. Heterozygosity of 36 northern highbush blueberry cultivars plotted against the number of cycles of selections (i.e., generations separating the cultivar from the farthest founding Vaccinium corymbosum clones).

breeding acting on many loci controlling a variety of traits. In SHB, heterozygosity and cycles of selection were not statistically associated $(r=-0.36 ; \mathrm{n}=23 ; P>0.05)$, suggesting that most of the loss of alleles occurred during the stage of germplasm enhancement; this genetic "erosion" could also explain why heterozygosity was not correlated with inbreeding coefficient in SHB.

\section{Conclusion}

In this study, we report the genetic contributions of seven Vaccinium species that constitute the current genetic base of cultivated SHB (Table 1) and demonstrate the usefulness of SSR markers to assess genetic relationships among SHB cultivars.

Previous studies in field crops have shown that pedigreebased diversity measurements can result in an overestimation of the actual level of genetic diversity in the gene pool as a result of the assumptions that are made regarding genetic drift, 
selection pressure, and the relatedness of ancestors with unknown pedigree (Cox et al., 1985; Kim and Ward, 1997; Soleimani et al., 2002). Our results were consistent with these studies in the sense that pedigree data tended to overestimate the effects of wide hybridization on genetic diversity of highbush blueberry, so our conclusion is that SHB are less genetically diverse than previously thought. First, levels of molecular relatedness within SHB were similar as those within NHB-historical (Fig. 4) despite the broader genetic base and larger pedigree distances in the former cultivar group (Table 1; Fig. 3). Second, NHB-modern and SHB cultivars exhibited similar levels of heterozygosity (Fig. 6) despite the considerably higher levels of inbreeding in the former cultivar group (Fig. 5).

Boches et al. (2006a) found that wild $V$. corymbosum accessions were genetically more diverse than cultivated NHB as assessed by SSR polymorphism. It is likely that this difference was caused in part by a founding event, i.e., when breeders choose only a few genotypes for all subsequent crop improvement (Hyten et al., 2006). Founding events are known to create genetic bottlenecks that can result in reduced heterozygosity, loss of rare alleles, and changes in allelic frequencies (Halliburton, 2004). Our research indicates that, after Frederick Coville's initial founding event, the heterozygosity of the cultivated highbush blueberry has continued declining as a consequence of selective breeding.

\section{Literature Cited}

Ballington, J.R. 1990. Germplasm resources available to meet future needs for blueberry cultivar improvement. Fruit Var. J. 44:54-62.

Ballington, J.R., S.D. Rooks, W.T. Bland, and A.D. Draper. 2006. The role of interspecific hybridization in the North Carolina State University blueberry breeding program. Proc. 10th North Amer. Blueberry Res. Ext. Workers Conf. p. 6-13.

Ballington, J.R., C.A. Walker, and A.D. Draper. 1984. Strategies for developing hexaploid blueberries adapted to spring frost- or freezeprone areas in the Coastal Plain of the southeastern United States. Proc. 5th North Amer. Blueberry Res. Ext. Workers Conf. p. 38-43. Bernardo, R., A. Murigneux, J.P. Maisonneuve, C. Johnsson, and Z. Karaman. 1997. RFLP-based estimates of parental contribution to $\mathrm{F}_{2}$ - and $\mathrm{BC}_{1}$-derived maize inbreds. Theor. Appl. Genet. 94:652-656. Bernardo, R., J. Romero-Severson, J. Ziegle, J. Hauser, L. Joe, G. Hookstra, and R.W. Doerge. 2000. Parental contribution and coefficient of coancestry among maize inbreds: Pedigree, RFLP, and SSR data. Theor. Appl. Genet. 100:552-556.

Boches, P.S., N.V. Bassil, and L.J. Rowland. 2005. Microsatellite markers for Vaccinium from EST and genomic libraries. Mol. Ecol. Notes 5:657-660.

Boches, P., N.V. Bassil, and L.J. Rowland. 2006a. Genetic diversity in the highbush blueberry evaluated with microsatellite markers. J. Amer. Soc. Hort. Sci. 131:674-686.

Boches, P., L.J. Rowland, K.E. Hummer, and N.V. Bassil. 2006b. Cross-species amplification of SSR loci in Vaccinium. Acta Hort. 715:119-128.

Brooks, R.M. and H.P. Olmo. 1997. Register of fruit and nut varieties. 3rd Ed. ASHS Press, Alexandria, VA.

Bruederle, L.P. and N. Vorsa. 1994. Genetic differentiation of diploid blueberry Vaccinium section Cyanococcus (Ericaceae). Syst. Bot. 19:337-349.

Camp, W.H. 1945. The North American blueberries with notes on other groups of Vacciniaceae. Brittonia 5:203-275.

Clark, J.R. and C.E. Finn. 2006. Register of new fruit and nut cultivars list 43. HortScience 41:1101-1133.

Coville, F.V. 1937. Improving the wild blueberry, p. 559-574. In: Yearbook of agriculture. U.S. Dept. Agr., Washington, DC.
Cox, T.S., Y.T. Kiang, M.B. Gorman, and D.M. Rodgers. 1985. Relationship between coefficient of parentage and genetic similarity indices in the soybean. Crop Sci. 25:529-532.

Darrow, G.M., D.H. Scott, and H. Dermen. 1954. Tetraploid blueberries from hexaploid $\times$ diploid species crosses. Proc. Amer. Soc. Hort. Sci. 63:266-270.

Draper, A.D. 1997. Blueberry breeding for the southern United States. Fruit Var. J. 51:135-138.

Draper, A.D., G.J. Galletta, and J.R. Ballington. 1982. Breeding methods for improving southern tetraploid blueberries. J. Amer. Soc. Hort. Sci. 107:106-109.

Draper, A.D. and J.F. Hancock. 2003. Florida 4B: Native blueberry with exceptional breeding value. J. Amer. Pomol. Soc. 57:138-141. Ehlenfeldt, M.K. 1994. The genetic composition and tetrasomic inbreeding coefficients of highbush blueberry cultivars. HortScience 29:1342-1345.

Ehlenfeldt, M.K. 1997. Breeding blueberries for the new century. Acta Hort. 446:227-233.

Enoki, H., H. Sato, and K. Koinuma. 2002. SSR analysis of genetic diversity among maize inbred lines adapted to cold regions of Japan. Theor. Appl. Genet. 104:1270-1277.

Falconer, D.S. and T.F.C. Mackay. 1996. Introduction to quantitative genetics. 4th Ed. Longman, Harlow, UK.

Halliburton, R. 2004. Introduction to population genetics. Pearson/ Prentice Hall, Upper Saddle River, NJ.

Hancock, J.F., W.A. Erb, B.L. Goulart, and J.C. Scheerens. 1995. Utilization of wild blueberry germplasm: The legacy of Arlen Draper. J. Small Fruit Viticult. 3:1-16.

Hancock, J.F. and J.H. Siefker. 1982. Levels of inbreeding in highbush blueberry cultivars. HortScience 17:363-366.

Hyten, D.L., Q. Song, Y. Zhu, I.-Y. Choi, R.L. Nelson, J.M. Costa, J.E. Specht, R.C. Shoemaker, and P.B. Cregan. 2006. Impacts of genetic bottlenecks on soybean genome diversity. Proc. Natl. Acad. Sci. USA 103:16666-16671.

Kim, H.S. and R.W. Ward. 1997. Genetic diversity in eastern U.S. soft winter wheat (Triticum aestivum L. em. Thell.) based on RFLPs and coefficients of parentage. Theor. Appl. Genet. 94:472-479.

Liu, K., M. Goodman, S. Muse, J.S. Smith, E. Buckler, and J. Doebley. 2003. Genetic structure and diversity among maize inbred lines as inferred from DNA microsatellites. Genetics 165:2117-2128.

Liu, K. and S.V. Muse. 2005. PowerMarker: Integrated analysis environment for genetic marker data. Bioinformatics 21:2128-2129.

Loiselle, F., G.C.C. Tai, B.R. Christie, and T.R. Tarn. 1989. Relationship between inbreeding coefficient and clonal selection in a potato cultivar development program. Amer. Potato J. 66:747-753.

Luby, J.J., J.R. Ballington, A.D. Draper, K. Pliszka, and M.E. Austin. 1991. Blueberries and cranberries (Vaccinium), p. 393-456. In: Moore, J.N. and J.R. Ballington (eds.). Genetic resources of temperate fruit and nut crops. Acta Hort. 290:393-456.

Lyrene, P.M. 2002. Breeding southern highbush blueberries in Florida. Acta Hort. 574:149-152.

Lyrene, P.M. and J.R. Ballington. 1986. Wide hybridization in Vaccinium. HortScience 21:52-57.

Lyrene, P.M. and W.B. Sherman. 2000. 'Star' southern highbush blueberry. HortScience 35:956-957.

Lyrene, P.M., W.B. Sherman, and R.H. Sharpe. 1997. 'Misty' southern highbush blueberry. HortScience 32:1297-1298.

Moore, J.N. 1989. Breeding, p. 45-74. In: Eck, P. and N.F. Childers (eds.). Blueberry culture. Rutgers University Press, New Brunswick, NJ.

Okie, W.R. 1999. Register of new fruit and nut varieties list 39. HortScience 34:181-205.

Okie, W.R. 2002. Register of new fruit and nut varieties list 41. HortScience 37:251-272.

Okie, W.R. 2004. Register of new fruit and nut varieties list 42 . HortScience 39:1509-1523.

Pejic, I., P. Ajmone-Marsan, M. Morgante, V. Kozumplick, P. Castiglioni, G. Taramino, and M. Motto. 1998. Comparative analysis 
of genetic similarity among maize inbred lines detected by RFLPs, RAPDs, SSRs, and AFLPs. Theor. Appl. Genet. 97:1248-1255.

Rooks, S.D., J.R. Ballington, R.D. Milholland, W.O. Cline, and J.R. Meyer. 1995. Inventory of pest resistance in blueberry genotypes in North Carolina. J. Small Fruit Viticult. 3:99-110.

Sharpe, R.H. 1953. Horticultural development of Florida blueberries. Proc. Florida State Hort. Soc. 66:188-190.

Sharpe, R.H. and G.M. Darrow. 1959. Breeding blueberries for the Florida climate. Proc. Florida State Hort. Soc. 72:308-311.

Sharpe, R.H. and W.B. Sherman. 1976. Flordablue and Sharpblue, two new blueberries for central Florida. Univ. Florida Agr. Expt. Sta. Circ. S-240.

Sjulin, T.M. and A. Dale. 1987. Genetic diversity of North American strawberry cultivars. J. Amer. Soc. Hort. Sci. 112:375-385.

Smith, J.S.C., E.C.L. Chin, H. Shu, O.S. Smith, S.J. Wall, M.L. Senior, S.E. Mitchell, S. Kresovich, and J. Ziegle. 1997. An evaluation of the utility of SSR loci as molecular markers in maize (Zea mays L.): Comparison with data from RFLPs and pedigree. Theor. Appl. Genet. 95:163-173.

Soleimani, V.D., B.R. Baum, and D.A. Johnson. 2002. AFLP and pedigree-based genetic diversity estimates in modern cultivars of durum wheat [Triticum turgidum L. subsp. durum (Desf.) Husn.]. Theor. Appl. Genet. 104:350-357.

Spiers, J.M., S.J. Stringer, A.D. Draper, and C.L. Gupton. 2002. 'Biloxi' southern highbush blueberry. Acta Hort. 574:153155

Tamura, K., J. Dudley, M. Nei, and S. Kumar. 2007. MEGA4: Molecular evolutionary genetics analysis (MEGA) software version 4.0. Mol. Biol. Evol. 24:1596-1599.

Tinker, N.A. and D.E. Mather. 1993. KIN: Software for computing kinship coefficients. J. Hered. 84:238.

U.S. Department of Agriculture. 2007. Vaccinium germplasm at the National Clonal Germplasm Repository, Corvallis, Oregon. 20 Oct. 2007. <http://www.ars.usda.gov/Main/docs.htm?docid=11371>. van Berloo, R. and R.C.B. Hutten. 2005. Peditree: Pedigree database analysis and visualization for breeding and science. J. Hered. 96:465-468

Vander Kloet, S.P. 1988. The genus Vaccinium in North America. Publ. 1828. Agr. Can. Res. Branch, Ottawa, Ontario, Canada.

Weakley, A.S. 2007. Flora of the Carolinas, Virginia, Georgia, and surrounding areas. 15 Mar. 2007. <http://www.herbarium.unc.edu/ flora.htm>. 